\title{
A UNIVERSAL INDEX FOR PSYCHOLOGICAL FACTORS
}

\author{
RAYMOND B. CATTELL
}

University of Illinois

\section{PRESENT RESPONSES TO THE NEED FOR INDEXING}

Growing recogniton of the ubiquitous and fundamental role of factor analysis in psychology - fortunately now matched by a visible increase in psychologists proficient in the effective application of the method-is likely to yield a large harvest of new structural, functional and taxonomic knowledge in the near future. Forseeing this, it is most important that we make available a well-thought-out and generally approved index system to escape from chaos. Without such a system the teacher and the researcher will soon have to begin any enterprise in this area by first groping through an endless scientific junk yard for the treasures they need. But with some forethought on organization, they might instead deal with a well-ordered and effectually applicable storehouse of tools and concepts. Our purpose is therefore to discuss basic principles for indexing, to express the opinions of authorities in the field with whom we have discussed the matter, and to start an index which may be continued by a proposed responsible committee.

The problem of an indexing and coding system is organically connected with the problem of testing, confirming and defining factors. Here we must confine ourselves only to indicating the technical highlights of the latter, leaving more extensive and detailed discussion to later papers. Yet it mustbe stressed that the growth of an index depends on the availability of means for adequate scientific surveys and of machinery for considered, scientific, democratic judgement on the data. Fortunately, through the technical conferences on factor analysis convened by the Educational Test Service, initial committees have been brought into existence in the last two or three years and have provided such a survey basis. There have also been the exhaustive surveys of personality factors by the present writer, covering diverse fields up to 1946 (2) and the specifically objective test field up to the present time (7), as well as the survey of ability factors by Guilfoid, up to 1947 (15) and the survey of personality factors in all media by French (13). The recent committee on ability factors, including, among others, Adkins, Bechtoldt, Carroll, Comrey, Coombs, Dudek, Dvorak, Fruchter, Guilford, Humphreys, Michael, Taylor, Thurstone and Zimmerman, has already proceeded as far as the compiling of an array of actual reference tests for ability factors, based on the committee's judgement, and edited by French (12); and a sub-committee with the present writer as chairman has considered personality factors.

As indicated above, our concern here extends to surveys and their methods only in so far as their standards and styles affect the discussion of essentials in classification and indexing. Index and survey have to be methodologically in step, and for its nourishment the index depends upon the growth of surveys. In most sciences successful taxonomic systems have had to compromise realistically between an ideal, timeless logic on the one hand, and the limits of vision in the historically existing data-as well as the limits of the social organization of science- on the other.

The historically given situation in psychology today - which closely resembles that of early chemistry or botany, or the more recent indexing of hormones and vitamins in 
physiology - is that half-a-dozen leading researches, intensively working in different fields, have statted symbol or naning systems, each appropriate to his own special field. Although each responsible laboratory can probably be depended upon not to make mistakes of duplication or inadequate identification within its own field, it is nevertheless true that complete chaos may, and frequently does, arise when overlapping is encountered among them. Thus Spearman started precise symbol reference with his unique " $g$ " and other lower case symbols - $f$, p, etc.--for fluency, rigidity and similar "group factors" (19). Thurstone (20) and Burt (2) broke into capitals, the former using initial letters for the carefully chosen names of his stabilized primary ability factors, V, N, S, etc. Guilford, using the same principle, started other series for his questionnaire factors and creative ability factors, while the present writer used alphabetical symbols for personality factors ordered according to diminishing contribution to the personality sphere (2).

Despite the admittedly superior attractiveness of letters--with their meretricious suggestion of giving meaning without the irrevocable connotations of a word-when compared with cold, impersonal numbers, this system has eventually to be abandoned. Already students experience confusion of the symbols of Guilford, Thurstone and the present writer. Furthermore, Thurstone has himself had to split his symbols, e.g into $S_{1}, S_{2}$ and $S_{3}$, and it might not be long before this system would force us into something like an automobile registration number, without either intrinsic meaning or simplicity.

While it is not proposed to abolish this use of initial letter symbols by local laboratories-for it may usefully linger, as provincial measurement systems lasted alongside the metric system - yet a scientifically more universal and geographically more international system must be sought. Initial letters, incidentally, would also have the defect of quickly losing their vestiges of meaning by translation. A first step from these limitations was taken in the present writer's use of alphabet symbols for variance order, covering personality factors A through O (4), regardless of verbal label. Although this compromise, following the practice of the vitamin researchers, is in the end inadequate, it introduces two useful principles, as follows:

(1) It insists that if the final, interpretive name is to be apt and permanent some appreciable time (for research) must elapse between (a), the discovery and operational definition of a pattern, as a reproducible entity, and (b), it's later understanding and scientific identification (or interpretation as a concept). Factors, as first discovered and confirmed by cross validation with new populations, are essentially only verified hypotheses as to patterns. Adopting initial letters of contingently interpretive names when a factor is first discovered therefore buys immediate convenience and status only at the cost of later trouble. In a surprising short time it confuses researchers with its progeny of questionbegging assumptions and chokes advance with the weeds of purely semantic problems. For example, $p$ looks innocent enough as a symbol for perseveration but is misleading when the stable but obscure factor turns out to be one of rigidity of disposition rather than perseveration of mental sets or "Einstellungen." While to talk of an R, or reasoning factor, invites confusions if different kinds or fields of reasoning are later found to require quite different factors.

(2) Using letters for factors in variance order promised to give the earlier alphabetical symbols to factors with larger and more obvious effects, which, incidentally, also tend to be the factors historically first identified. Thus some immediate meaning inheres in such a symbol. However, this principle of variance order has in fact turned out not 
to be so important or so valid as the first. Indeed it has eventually to be renounced, because symbols cannot conveniently be juggled every time a newly discovered factor intrudes into the variance hierarchy and because the "universe of tests" cannot readily be defined. From experiences of this system we emerge with the conclusion that lettering or numbering recording to order of discovery is a better principle. For this is practicable and at the same time tends to give a rough approximation to the rather useful connotation of the above order of salience of factor effects.

\section{REQUIREMENTS IN AN EFFECTIVE INDEX SYSTEM}

Existing indexing principles, or lack of principles, having thus resulted either in actual or imminent confusion, we are entitled to abandon a tangle of precedents and set up a New World of logic. With the will to make a fresh start, we may consider the following as basic guides:

(1) The number of factors in psychological transactions is likely to be nearer two hundred than twenty. Already Guilford claims that the number of known independent factors is about one hundred. No alphabetical system, Greek, Roman or other, will comprehend them. Though letters may be easier to remember than numbers we are therefore forced to accept numbers for any final system, though small secondary index system of letters may continue to be practicable in clearly limited fields.

(2) A number system, being absolutely non-committal as to interpretation, permits a factor to be discussed, reproduced, and experimented upon, with ample time for the customary vacillation of fashions in interpretation, or for its being kicked around in debate, until a generally-acceptable, insightful name settles alongside the number.

(3) A single numerical series, in contrast to insular series for each laboratory or area, ensures that any claim to a factor being new shall be more carefully verified by seeing that it does not duplicate any pattern already existent in the total series.

(4) Science is universal, but an initial letter code cannot be, due to language differences. It is surely not being excessively foresighted to aim at an index that will be internationally acceptable and useful.

(5) However, there are certain broader circumstances that we have yet discussed, which require that the number series be qualified by a symbol indicating its subdivision within a larger framework of experimental and factoring conditions. There appear six such experimental conditions, not all of which are yet relevant enough in practice to require code symbols, as follows :

(a) There could be separation of series into the modalities of cognitive, dynamic and temperament traits. Though an operationally conceived theoretical basis can be suggested for this division (2) it has not as yet been widely discussed and even when accepted it might leave doubts in practice in some cases. Our present vague, popular divisions are no use at all. There are certainly historical instances of the same factor being named independently in temperament and in ability series, and recently there have been cross-matchings of supposedly perceptual and supposedly personality factors (7). Though personality and ability divisions may continue as rough guides for research and objects of theoretical debate, the actual existence of even a few cases in an index system on which researchers disagree, and that consequently, to satisfy both, have to be carried in two series, would wreck the functioning of modality classification. It seems best therefore to abondon any attempt to subdivide the final series on this basis and, instead, to 
run ability and personality factors in the common category of "dimensions of individual behavior," in a single major series.

(b) Similarly no divisions according to computing method or method of factor extraction or rotation are called for, since the object of all methods is an identical, unique, scientifically-meaningful solution. Temporarily, until experience clears present doubts, it may be desirable to keep an index in terms of oblique simple structure and secondorder factors on the one hand and corresponding orthogonal factors on the other. But there would be no point in keeping indices for factors that are mere mathematical rather than scientific abstractions, for they would have no claim to invarince and universal relevance.

(c) On the other hand, until we have further evidence that Q-technique arrives at demonstrably the same factors as R-technique, and that individual, "unique-trait,". $P$-technique patterns scatter normally about the R-technique mean, it would seem desirable to prefix R-, P-, etc. to the series concerned. However, this also is in practice unnecessary until far more data than now exists accumulates in P-, Q-, T-, etc. techniques (2). Indeed, the only adequate population of factors tor classification exists at present in Rtechnique, whence $\mathrm{R}$ can be "taken as written."

(d) Separate series must be set up for different kinds of population. Factors survive sampling differences (20) and some recognizably survive differences in the very species of the parent population (7); but in general it would seem desirable to add a distinct letter suffix to the factor number to indicate $a$ adult, $c$ child, $p$ psychotic, etc. at least until it is proved that the dimension in question applies to all of these groups.

(e) Primary, first-order factors should not be confused with second-order factors. Little is yet known about the latter, but we might assign to them Roman numerals, since they will probably be few.

(f) It does seem desirable to separate, at least initially, the factors founded in different media of observation, namely, (1) Life recorded data or Behavior rated in situ, symbolized by the prefix L, (2) Q-data, in terms of questionnaire items accepted as introspective evidence, and (3) T- (or OT-) data, leading to factors in objective tests, i.e., behavioral, reproducible situations, including "projective" missperceptive measures, objectively scorable.

The contingent separation of $\mathrm{L}, \mathrm{Q}$, and $\mathrm{T}$ factor series thus proposed seems required by two considerations: (i) The early hopes that personality factors would always express themselves in all three media, producing a simple one-to-one parallelism which would lead to a single series has not been completely borne out by experiment $(4,8)$. Some factors penetrate all media, but in others the relation appears to be that of a more complex derivation. (ii) The usual proof that a factor is new and requires a new index number cannot be given "by inspection" in a mixed-media series. For the new factor in any one medium could not have marker variables in common with all earlier factors, some of which would be in other media, whence its novelty could not be demonstrated. Additional experiment will always be necessary, in the style of the Cattell and Saunders "interfactor" studies (8), to check across media, and this requires some lapse of time.

In time a special "Final Series" may be and should be set up of factors demonstrated to run through all three media series. But it is likely to be ten years hence before sufficient data and sufficiently widely accepted interfactor matching methods are available to provide a list of any appreciable length. Meanwhile we are on safe ground 
in separately evaluating and building $L, Q$ and $T$ series. Parenthetically one may add that there are practically no ability factors yet located in $L$ and $Q$ data anyway, and a trans-medium series may long remain impracticable there.

\section{PROPOSED CODE FOR SUBDIVISIONS}

Let us now see what the above considerations suggest in terms of an ideal code or indexing system, as distinct from one compromising with existing historical accidents. Evidently it must have the following six successive, lexicographic ${ }^{1}$ subdivisions, with their accompanying code signs.

1. First it would be understood that the factors concern dimensions of behavior in buman individuals, not of animals, human groups, culture patterns or other possible "individual organism" entries into correlation series that have been, or could be, used in factor analyses. This being "understood," no symbol would be required, in the present index, to indicate that we deal with human behavior dimensions.

2. A capital R, P, or $T$ should, strictly, prefix the series, to indicate in which of the three basic factor analytic designs (6) the patterns exist, for individuals. For another decade this code may remain unnecessary, as $\mathrm{R}$ is understood to contain the only sufficiently extensive data.

3. A second capital, $L, Q$ or $T$, should be prefixed to indicate whether the factor is founded in the life record (in situ, behavior rating), the questionnaire (self assessment) or the objective test medium. This is necessary right now.

4. The factor number should then follow, in Arabic numerals for first-order factors and Roman for second-order.

5. A subscript $c, a, p$, etc. should follow to indicate whether the factor is established in child, adult, psychotic or some more specialized population subdivided from these or other parent population species.

6. If agreement is later reached on a clear principle (2) for separating ability, temperament and dynamic factors, a superscript, $a, t$ or $d$ could be added. This would indicate the relation of the main Universal Index to any separate index systems set up for separate modalities, but would be superfluous in the Main Index itself since the number would already identify the factor. It would only aid the completion of that immediate description which is conveyed in the two prefixes and the subscript. However, at present there would be many opinion differences to be reconciled before this aspect of indexing could be settled. For example, though we have spoken in terms of three basic modalities, Guilford suggests seven separate factor lists, for factors in intellectual, psychomotor, achievement, interest, attitude, temperament and physiological data.

\section{SURVEY STANDARDS AND THE FOUNDATION OF INDEX}

With this brief, but, we hope, sufficiently logically exhaustive treatment, we can turn to setting up the actual indices, thereby both testing and illustrating the principles involved. The surveys on which this Index rests are the 1946 and 1947 surveys of person-

I use the term "lexicographic" for a hierarchy of subordinate subdivisions within subdivisions, but this special form of hierarchy is also the logicians' " tree of Porphyry," or Burt's (1) four factor theorem, or the same principle as was represented in my earlier borrowing of the term "genealogical" (5). Since Coombs has recently introduced the present term in connection with psychological scaling (10), in precisely this sense, I think his term may better recommend itself to psychologists. 
ality factors $(2,3)$ in ratings and questionnaires; the ability factors confirmed by French and his committee (12); the ability and personality factors in French's recent survey (11, 13) and the invariant Objective Test personality factors in my own recent survey (7).

In the $T$ series, granted that no sharp line can eventually be drawn between ability, perceptual and personality factors, I have given the first sixteen numbers to the historically first confirmed primary ability and perceptual factors and have then followed with the eighteen personality factor patterns which seem confirmed in three or more independent factorizations. Already there are two or three ability factors confirmed by third or fourth researches since the committee finished its first survey, and these should immediately follow. However, I have listed from these only General Reasoning, as Factor 34, for on this only has a consensus been immediately obtainable before listing. After these relatively distinct personality and ability factors there should follow, I suspect, the un-certain modality factors comprised by Guilford, Wilson and Christenson's factors in the creative ability area (16) and then the ergic and sentiment factors found by my co-workers and others in dynamic responses and recorded by French (13) as well as those found by Guilford interests.

In the Q-data, though French has comprehensively surveyed the field, and indicated proposed factor markers, neither an individual nor a committee has attempted to say which factors reach the acceptably high degree of independent confirmation necessary for final indexing, and, indeed, statistical matching tests have only been applied in limited sets of researches. Guilford has made an unpublished survey in which he indicates that he can provide marker variables (items in this case, ten to a factor) for as many as forty factors. A liberal interpretation of "established" would, in the present writer's opinion, lead to practically this number being considered; but it seems most important in initially setting up an index, before a permanent committee is established, to err on the side of scepticism and conservatism.

Both in the $\mathrm{L}$ series (which the present writer has twice surveyed $(2,3)$ ), and in the $Q$ series, the same rigorous standards have been adopted, (and applied to French's, Guilford's and the present writer's collations) as were applid in the $T$ series, namely a minimum of four known independent studies with the same pattern. However, since no committee has yet actually agreed on markers for these, they must be accepted as more tentative. Where the markers are not readily obvious from the published collations the present writer will be pleased to make available to researchers additional data, as yet unpublished, which would aid in determination of the best markers.

\section{A BEGINNING OF L, $Q$ AND $T$ INDICES}

Factors Established in the Life Record, Behavior Rating, Clinical Data. The LMedium, i.e. Behavior in situ, including BR Factors. In this series I have designated the factors both by the names and initials of French's survey (13) - first-and of my own $(2,3,7)$ second title-(when they also exist in the latter). The numbering is in approximate declining order of salience of the factors, in terms of number of researches, length of discovery, magnitude of variance, (in contribution to all variables), etc.

There are about ten more tolerably defined factors to be considered here, awaiting additional confirmatory research, and ten further ones for which some evidence exists.

Factors Estnblished in Questionnaire, Self-Descriptive Items, i.e. Data Not Permitting a 


\begin{tabular}{|c|c|c|c|}
\hline $\begin{array}{l}\text { Universal } \\
\text { Index } \\
\text { (U.I.) No. }\end{array}$ & $\begin{array}{l}\text { Local Lab } \\
\text { Letter Ind } \\
\text { French C }\end{array}$ & & $\begin{array}{c}\text { Existing Index Symbols and Names in Series (13) and } \\
\text { Series }(2,3,7)\end{array}$ \\
\hline U.I. L1 & $A$ & $A$ & Agreeableness (13); $A$ Cyclothymia-vs-Schizothymia $(2,3)$ \\
\hline U.I. L2 & $\boldsymbol{G}$ & $B$ & Intelligence (13); B Intelligence \\
\hline U.I. L3 & $E$ & C & $\begin{array}{l}\text { Emotionality (13);C Emotionality-Neuroticism-vs-Ego } \\
\text { Strength }(2,3)\end{array}$ \\
\hline U.I. L4 & $E_{i}$ & $D$ & Emotional Immaturity; $D$ Sthenic Emotionality $(2,3)$ \\
\hline U.I. LS & Do & $\boldsymbol{E}$ & Dominance $(13) ; E$ Dominance $(2,3)$ \\
\hline U.I. L6 & Su & $F$ & Surgency $(13) ; F$ Surgency $(2,3)$ \\
\hline U.I. L7 & Pe & $G$ & Persistence (13); G Super-ego Strength $(2,3)$ \\
\hline U.I. L8a & $S_{a}$ & $H$ & $\begin{array}{l}\text { Sociability or Manic Sociability } M a(13) ; H \text { Adventurous } \\
\text { Cyclothyma }(2,3)\end{array}$ \\
\hline U.I. L9 & Se & $I$ & Se, Sensitive Attitude (13); I Sensitive Emotionality $(2,3)$ \\
\hline U.I.. L10 & $D t$ & & Deterioration (13) \\
\hline U.I. L11 & $\mathrm{Cu}$ & $\boldsymbol{K}$ & Culture, and possibly $\operatorname{De}(13) ; K$ Cultured Mind $(2,3)$ \\
\hline U.I. L12 & $P_{s a} \mathcal{E}_{p}$ & $L$ & Paranoid Schizophrenia (13); L Paranoia $(2,3)$ \\
\hline U.I. L13 & $C_{2}$ & $M$ & Conventionality (13); $M$ Practical Concernedness $(2,3)$ \\
\hline U.I. L14 & & $N$ & Sophistication $(2,3)$ \\
\hline U.I. L15 & $A x$ & $O$ & Anxiety (13); $O$ Anxious Excitability $(2,3)$ \\
\hline U.I. L16 & Pc & $P$ & Psychotic Tendency (13); P Personality Disintegration' \\
\hline U.I. L17 & $H y$ & & Hysteria (13) \\
\hline U.I. L18 & $E x$ & & Excitement (13) \\
\hline
\end{tabular}

1 This is $P$ in the present writer's series, but not yet published. There is some question as to whether it should be considered a second-order factor. Eysenck argues that the equivalent $T$ factor is second-order, but the conclusion is not yet, in the present writer's opinion, reached on adequate grounds.

Second Observer, or $Q$ Data. Again the designations are given in both French's and my own labels and the numbers are assigned roughly in declining order of length and breadth of research basis. As far as is compatible with the latter $I$ have preserved, for maximum simplicity, the same relation of the number code to my letter code $(2,3,9)$ as in the $\mathrm{L}$ series; which also ensures that where an $\mathrm{L}$ and a $\mathrm{Q}$ factor are likely to be the same they will share the same number in this and the above medium.

$\begin{array}{ll}\text { Universal } & \text { Local Lab. } \\ \text { Index } & \text { Letter Indices : } \\ \text { (U.I.) No. } & \text { French Cattell }\end{array}$

\begin{tabular}{|c|c|c|c|}
\hline U.I. Q1 & $A$ & $A$ & Agreeableness $^{1}$ (13); A Cyclothymia-vs-Schizothymia \\
\hline U.I. Q2 & Pc & & $(2,9)$ Psychotic Tendency (13) \\
\hline U.I. Q3 & $E$ & C- & $\begin{array}{l}\text { Emotionally (13); C- General Emotionality-vs-Ego } \\
\text { Strength }\end{array}$ \\
\hline U.I. & $A u$ & & Autistic Tendency (13); Unnamed Factor 9 in $(2,9)$ \\
\hline U.I. Q5 & $D_{0}$ & $E$ & Dominance $(13) ; E$ Dominance $(2,9)$ \\
\hline U.I. Q6 & Su & $F$ & Surgency (13); F Surgency-vs-Desurgency $(2,9)$ \\
\hline U.I. Q7 & Pe & $\boldsymbol{G}$ & Persistence $(13) ; G$ Super-ego Strength $(2,9)$ \\
\hline U.I. Q8 & So & $H$ & Sociability (13); $H$ Adventurous Cyclothymia $(2,9)$ \\
\hline U.I. Q99 & Se & $\boldsymbol{I}$ & Sensitive Attitude (13); I Emotional Sensitivity $(2,9)$ \\
\hline
\end{tabular}


U.I. Q10 (Not in $L \quad L$ Paranoid Tendency $(2,9)$

French's survey)

U.I. Q11 $S_{n}-M$ Lack of Self-consciousness ${ }^{2}$ (13); $M$ Hysteric Unconcernvs-Practical Concernedness $(2,9)$

U.I. Q12 Sf $\quad N$ Sophistication (13); $N$ Sophistication

U.I. Q13 Cd $O$ Cycloid Tendency (13); $O$ Anxious Excitability $(2,9)$

U.I. Q14 Ip-Re $Q_{1}$ Interest Philosophy-vs-Religion ${ }^{3}$ (13); $Q_{1}$ Radicalism-vsConservatism $(2,9)$

U.I. Q15 Ss $Q_{2}$ Self-sufficiency (13); $Q_{2}$ Independent Self-sufficiency $(2,9)$

U.I. Q16 Ne $Q_{3-}$ Nervousness $(13) ; Q_{:-}$Lack of Will and Stability $(2,9)$

U.I. Q17 (Not in $Q_{4}$ Nervous Tension (Somatic Anxiety) $(2,9)$

French's survey)

$\begin{array}{lll}\text { U.I. Q18 } & R h & \text { Rhathymia4 (13) } \\ \text { U.I. Q19 } & S c & \text { Self-confidence (13) } \\ \text { U.I. Q20 } & M f & \text { Masculinity-Femininity (13) }\end{array}$

1 As indicated above, certain complications made the Q-factor indexing necessarily more tentative than the others. However, I have omitted no factor from French's survey (apart from the dynamic, special interests realm) that is confirmed in four or more studies, except his "Gregariousness." I would argue that this is the same as Factor I, and since no researches are common to the two factor discoveries in this case there exists at least no disproof of my inference. If " linking" researches prove this condensation to be wrong the $\mathrm{Gg}$ factor could be recorded as Factor 21.

2 Again there are insufficient common variables in $S_{n}$ - and $M$, so the condensation of $S_{n}$ into this factor may need revision.

${ }^{3}$ Again I argue for the condensation of two of French's factors; but suggest Re be retained here if a new number has to be found for $I p$

4 Conversely, in this case French presents evidence that the factor which Guilford and $I$ have considered one, but had independently named Rhathymia and Surgency, is really two. I suggest thecefore that Surgency be allocated to the pattern which has emphasis on speed, cheerfulness and talkativeness (See Saunders (18), in (13) and Rhathymia for the pattern with stronger emphasis on happy-go-lucky, carefree attitudes (also with talkativeness).

Factors Established in Objective Tests. ( $\mathrm{T}$ factors: Controlled, reproducible situations and objective, behavioral-response scoring.) As far as names for personality factors are concerned I have confined myself to the most recent survey ( 7 ) with its more exacting and objectively statistical matching procedures, mistrusting any naming system which attempts definitely to assimilate these factors by psychological intuition alone to the previous $L$ or $Q$ factors, before inter-factorizations have actually checked. As far as ability factors are concerned I have exactly followed the verdict of the E.T.S. committee and have put their agreed fifteen factors $(11,12)$ first $(1$ through 15$)$ because they are historically first confirmed, and followed them with the eighteen personality factors (7). The more recent ability factors, in the creative activity area, should presumably follow when independent researches concur on their patterns, as also should the ergic and interest factors noted by French (13) and the interest factors of Guilford, Wilson and Christenson.

Second order series:

Universal

Index No.

$\begin{array}{ll}\text { U.I. -TI } & \text { General Ability }(1,19,21) \\ \text { U.I. TII } & \text { Bodily Tempo }(17)\end{array}$


First Order, Primary Factor Series :

Universal Local

Index No. Laboratory

$\begin{array}{lll}\text { U.I. T1 } & A & \text { Aiming (Eye-hand Coordination) (12) } \\ \text { U.I. T2 } & C f & \text { Flexibility of Closure (12) } \\ \text { U.I. T3 } & C & \text { Speed of Closure (12) } \\ \text { U.I. T4 } & D & \text { Deduction (12) } \\ \text { U.I. T5 } & I & \text { Induction (12) } \\ \text { U.I. T6 } & \text { If } & \text { Ideational Fluency (12) } \\ \text { U.I. T7 } & M a & \text { Associative Memory (12) } \\ \text { U.I. T8 } & M k & \text { Mechanical Knowledge (12) } \\ \text { U.I. T9 } & M s & \text { Motor Speed (12) } \\ \text { U.I. T10 } & N & \text { Number Facility (12) } \\ \text { U.I. T11 } & S & \text { Spatial Relations and Orientation (12) } \\ \text { U.I. T12 } & S d & \text { Speed of Symbol Discrimination (12) } \\ \text { U.I. T13 } & V & \text { Verbal Knowledge (12) } \\ \text { U.I. T14 } & V z & \text { Visualization (12) } \\ \text { U.I. T15 } & W & \text { Word Fluency (12) } \\ \text { U.I. T16 } & C a & \text { Competent Assertiveness (7) } \\ \text { U.I. T17 } & R t & \text { Restraint-Timidity (7) } \\ \text { U.I. T18 } & H o & \text { Hypomanic Overcompensation (7) } \\ \text { U.I. T19 } & C e & \text { Critical, Dominant Exactness (7) } \\ \text { U.I. T20 } & S \text { Sy } & \text { Sociable Willingness (7) } \\ \text { U.I. T21 } & E d & \text { Energetic, Fluent Decisiveness (7) } \\ \text { U.I. T22 } & N r & \text { Nervous, Alert Reactivity (7) } \\ \text { U.I. T23 } & N r & \text { Neural Reserves-vs-General Neuroticism (7) } \\ \text { U.I. T24 } & A p & \text { Anxiety Proneness (7) } \\ \text { U.I. T25 } & A r & \text { Accurate Realism-vs-Psychotic Tendency (7) } \\ \text { U.I. T26 } & C i & \text { Cultured, Introspective Self-control (7) } \\ \text { U.I. T27 } & A t & \text { Apathetic Temperament (7) } \\ \text { U.I. T28 } & E e & \text { Sociable, Emotional Evasiveness (7) } \\ \text { U.I. T29 } & S e & \text { Sympathetic Energy Mobilization (7) } \\ \text { U.I. T30 } & I s & \text { Indepepdent, Super-ego Stolidity (7) } \\ \text { U.I. T31 } & W r & \text { Wary Realism (7) } \\ \text { U.I. T32 } & S i & \text { Schizoid Inhibitedness (7) } \\ \text { U.I. T33 } & D o & \text { Dourness (7) } \\ \text { U.I. T34 } & R & \text { General Reasoning Ability (12) } \\ & & \end{array}$

1 Should my contention (7) be verified that ability factors T2, T3 and T6, as first perceived within the restricted matrices of ability factorizations, are really personality factors $T 19, T 17(-)$, and T21 respectively, there would be no difficulty in finding other sufficiently important ability factors to which to assign these vacated numbers. But the decision needs some years of research to determine the relative loadings discernible with improved personality and ability measures on the given factors. However, this instance of certain ef Thurstone's perceptual ability factors being equally or more highly loaded in personality tests at least emphasizes the impossibility at present of making separate seties for trait modalities (as distinct from test media). 


\section{COORDINATIONS REQUIRED FOR IMPROVEMENT}

The above index of 18 life record factors, 20 questionnaire factors and 34 objective test factors, in the realm of personality (including ability) is presented as a reference system which may recommend itself to many workers in the field for initial use, despite being imperfect and incomplete. It is imperfect in the sense that although two to six sound marker variables can be presented to define and locate each factor, the interpretations of the factors, through external validation, and study of their general "natural history," are still lacking, so that in the main we have to retain the above rather clumsy but maximally descriptive phrases instead of neat interpretive labels. It is incomplete in the sense that nearly twice as many factors, on a good experimental basis, could right now be found by the diligent searcher; yet, as indicated above, I have erred on the side of caution, refraining from including such factors until the additional evidence exists to show * that they are confirmed in other populations and not duplicating factors already listed.

It must be insisted upon that for the further growth and improvement of this Universal Index of Factors a standing and preferably international comittee is needed that will set out definite standards of factor verification, and publish, annually or biennially, a supplement defining newly confirmed factors, based on a comprehensive survey of fresh research, and accompanied by actual marker test batteries for the factors. The writer would tentatively suggest that the ad hoc committees already in intermittent operation in the U.S. should coopt other members and form a standing Committee of the A.P.A. for Indexing Psychological Factors, which could invite cooperation from similar committees formed in the British Psychological Society and in such countries as Sweden and Switzerland where appreciable factor analytic findings have also accumulated in the literature.

For the purpose of immediately continuing the surveys in the field of personality the present writer has proposed that the personality subcommittee comprised by Guilford, French and himself, should coopt additional American researchers with special knowledge, and maintain contact with such individual representatives of factor analytic work in other countries as Burt, Eysenck and Vernon in Britain, Hammer and Walker in Australia, Taylor in South Africa, Vidal and Pichot in France, Meili in Switzerland, Meschieri in Italy, Bergmann and Strunz in Germany, and Husen in Sweden. With quite small financial aid for secretarial, recording and reproduction work such an organization could enormously increase the effectiveness of research effort, avoid duplication, spread laborsaving computing devices, reduce the Babel of misunderstanding in communications, and introduce the possibity of a true over-all research strategy. On the other hand, since it must be admitted that even in the super-national world of science local traditions die hard, the combined difficulties of language and methodological differences might at first challenge the success of any extensive Universal Index, and so our inmediate efforts should be to "let charity begin at home" and to establish first some core of agreement among Englishspeaking psychologists.

For the present, in America, Dr. G. French, at the Educational Test Service, Princeton, New Jersey, has expressed his willingness to act as secretary and to receive suggestions from psychologists anywhere concerning factors which are deemed to be sufficiently established for the committee to assign a code number in the Universal Index and to define a standard set of marker variables. It would be particularly valuable in this connection if researchers would call the committee's attention to unpublished Ph.D. 
theses. The effective and optimal standards which such a committee could adopt for research practice can only be discussed fully elsewhere and with increasing experience, but the following might be taken as an initial indication: (1) Researches on a minimum population of 100 cases, (2) Certain limits of reliabilities of variable measurements, (3) Satisfactory application of tests of completeness of factor extraction, (4) Proof of sufficient convergence upon simple structure or on some other criterion of rotation, (5) Inclusion of three to six marker tests for hypothesized factors, (6) Testing of agreement of factor patterns by correlation or the use of the marker coincidence index (7). (As to markers, the existing ability factor committee has proceeded with three per factor, two being the theoretical minimum; but in personality factors, where it is much harder to get tests with high loadings, the battery set out by the present writer for 18 factors (7) keeps to a minimum of six marker tests per factor, without overlap. However, the question of standards is a complex one, requiring more flexible treatment than is possible in a brief reference here.)

It is possible that to some psychologists, only peripherally concerned with this field, the present detailed concern with a Universal Index, and the above analysis of indexing principles, may assume the air of an unduly pedantic exercise. But anyone familiar with the theoretical and practical problems of research in this area will recognize that it is something far more vital. As the committees and individuals have commented $(7,13)$, their surveys reveal a shocking wastage of effort, with perhaps one-half of all studies unintegratable, and this has occurred largely through lack of any sacial organization of research, e.g. lack discussed marker variables, unawareness of requisite standards for invariance, and poor communication on improved computing methods or on persistent hidden difficulties. A widely available index, on a sure foundation, will not only avoid wasteful repetition, enable new areas to be represented with maximum efficiency, and provoke research in the right places by indicating the more neglected phenomena, but also suggest the theoretical problems needing timely attention for integrating the field.

In conclusion, it is not suggested that the universal numerical index should replace the existing local laboratory letter initials, etc. Although a glance even at the present brief lists above will show up that confusion in the letter systems which has already been described, yet it is necessary to have some accepted temporary limbo in which factors may serve their apprenticeship to truth. In this way they may preserve their identity in convenient form for discussions and transactions within the specific group of psychologists concerned, in the few years between discovery and adequate confirmation. But, once confirmed, they could with great advantage always be referred to in discussion by the U.I. number, whatever other temporary names or hypothetical interpretations are being entertained.

\section{REFERENCES}

1. Burt, C. L. Factors of the mind. London: Univ. of London Press, 1940.

2. Cattell, R. B. The description and measurement of personality. New York: World Book Co., 1946.

3. Cattell, R. B. Confirmation and clarification of primary personality factors. Psychometrika, 1947, 12, 197-220.

4. Cattell, R. B. Personality: A systematic theoretiad and factual study. New York: McGraw-Hill, 1950.

5. Cattell, R. B. Factor Analysis. New York: Harper, 1952.

6. Cattell, R. B. The three basic factor analytic research designs: their interrelations and derivatives. Psychol. Bull., 1952, 49, 499-520.

7. Cattell, R. B. The principal invariant personality factors established in objetive tess. Adv. Publ. No. 1, 
Lab. of Person. Asseas. and Group Behav., Univ. of Illinois, Urbana, III., 1953.

8. Cattell, R. B., \& Saunders, D. R. Inter-relation and matching of factors from behavior tating, questionnaire and objective test data. J. soc. Psychol., 1950, 31, 243-260.

9. Cattell, R. B., Saunders, D. R., $\propto$ Stice, G. F. The 16 personality factor test. Champaign, III.: Institute for Personality and Ability Testing. 1950.

10. Coombs, C. H. Mathematical models in psychological scaling. I. Amer. stat. Ass., 1951, 46, 480-489.

11. French, J. W. The description of aptitude and achievement tests in terms of rotated factora. Psychol. Monogr. No. 5, 1951.

12. French, J. W. Selected tests for reference vectors. Princeton : Educ. Test Service, 1953.

13. French, J. W. The description of personality measurements in terms of rocated factors. Princeton: Educ. Test Service, 1953.

14. Guilford, J. P. Personality factors S, E and M and their measurement. J. Psychol. 1936, 2, 108-128.

15. Guilford, J. P. The discovery of aptitude and achievement variables. Science, 1947, 106, 279-282.

16. Guilford, J. P., Wilson, R. C., \& Christenson, P. R. A factor analytic study of creative thinking, II Administration of tests and analysis of results. Los Angeles, U.S.C. Psych. Lab., 8 July, 1952.

17. Rimoldi, H.J.A. Personal rempo. J. abnorm. soc. Psychol., 1951, 46, 283-303.

18. Saunders, D.R. A further investigation of the relations between questionnaire and behavior eating personality factors. (In (13)).

19. Spearman, C. The abilities of man. London: Macmillan, 1932.

20. Thurstone, L.L Primary mental abilities. Chicago: Univ. of Chic. Press, 1938.

21. Thurstone, I L. Multiple factor analysis. Chicago: Univ. of Chic. Press, 1947.

MS. received X 20, 57.

Raymond B. Cattell (1905- ), Research Prof., Laboratory of Personality Assessment and Group Behavior, Univ. of Illinois, Urbana, Illinois, U.S.A.

\section{THE U.S. AND JAPAN}

Prof. R. B. Cattell, made a round-the-world trip, visiting Australia and Calcutta (the Indian Institute of Statistics) this summer, but could not have time to come to Japan.

Dr. M. A. Wenger, Professor of Psychology at UCLA, visited Japan on his way to India and back home, and had talks and lectures with a number of physiologists and a couple of psychologists in Tokyo and Osaka. It is said he stayed in India from the middle of January to the middle of June this year, chiefly at Mysore University and at the University of Poona. The Editor met him at UCLA just after the APA Convention of 1955 , and hearing that he was going to India, suggested him to investigate Yoga training with his research methods, but to the great regret, could not hear about his achievements in India by the interruption of mutual communication.

Prof. Jyuji Misumi, an assistant professor of educational psychology at Kyushu University, returned to Japan at the end of March, promoting mutual understanding and friendship in India and Ceylon as well as in European countries, after his six months' study at the Research Center for Group Dynamics, University of Michigan, and attending 1956 summer session of the National Training Laboratory in Group Development at Bethel, Maine, U.S.A.

Prof. Tadashi Tsushima, an assistant professor of clinical psychology at Kyoto Prefectural University, and Mrs. Tsushima returned home in October after their stay of two years at the University of Illinois. He studied under Prof. O.H. Mowrer and she studied ed ucational psychology under Prof. Hastings and Prof. Cattell. They will help the Editor ever more in the communication with our colleagues in the U.S. and in Asian countries, and in editing the journal.

Prof. Jitsuro Kuroda, an assistant professor of psychology at Seiwa Women's Junior College, Kobe, returned home after two years' study in the U. S., one year at Brown University and another at Peabody College. Prof. Fujio Tomoda of Kokugakuin University, Tokyo, who has studied intensively the nondirective counseling method with Japanese clients and translated a series of Dr. Rogers' works into Japanese, is now at the Counseling Center of the University of Chicago and will move to Madison in January to study under Prof. Rogers, who is now at the University of Wisconsin. 